\title{
The Story of Chinese Characters (0051-0060) When Translated On Korean Pronunciation
}

\author{
Hyeonhi Regina Park1, Kunjoo Daegon-Andrea Kim², Jiah Anna Kim³, Alain Hamon ${ }^{4}$ Rosa Kim5, Sohwa \\ Therese Kim${ }^{6}$, Sangdeog Augustin $\mathrm{Kim}^{7^{\star}}$ \\ 1Department of Elderly care and welfare, Joongbu University, Kumsan, Republic of Korea ROK \\ 2Department of History, Yonsei University, Seoul, ROK \\ ${ }^{3}$ Department d'Expertise economique, Universite de Paris-Est Creteil, Paris, France \\ 4 L'Ecole Internationale Jean-Mermoz, Abidjan, Cote d'Ivoire, \\ ${ }^{5}$ Specialite d'Economie politique, Ecole des Hautes Etudes en Sciences Sociales (EHESS), Paris, France \\ ${ }^{6}$ Department of French language and literature, Seoul Women's University, Seoul, ROK, \\ ${ }^{7}$ Department of Companion animal and animal resources science, Joongbu University, Kumsan, ROK \\ *Corresponding Author \\ Sangdeog Augustin Kim
}

\section{Article History}

Received: 27.11.2019

Accepted: 04.12.2019

Published: 14.12 .2019

\begin{abstract}
It is well known that Chinese people have been responsible for the Chinese character, but the meaning of Chinese characters themselves is not well understood until now. The present researchers chose by chance the Chinese characters, and counted them into the number of letters from 0051 to 0060 . From the parts of Chinese characters the researchers tried to find the appropriate meaning in Korean language of the several parts of the Chinese characters. Through this research of Chinese characters, the researchers have found that the original meaning is more concrete than the presently used meaning. For example, the original meaning of $A$ (我) is "I who am not a special man (woman), but am an ordinary and simple man (woman)"; while it's present meaning is changed into "I, myself".
\end{abstract}

Keywords: The original meaning of $A$ (我) is "I who am not a special man (woman), but am an ordinary and simple man (woman)"; while its present meaning is changed into "I, myself", number of letters from 0051 to 0060 , several parts of the Chinese characters, in Korean language.

\section{INTRODUCTION}

It is well known that the Chinese people have been responsible for the Chinese character [1], but the meaning of Chinese characters themselves is not well understood until now. Anyway, not only the Chinese people but also the Korean people have used the Chinese letter for long time [2]. The present researchers prepared several reports about Tcheonzamun (The thousand character essay) translation on Korean pronunciation [3] and on the story of Chinese characters when translated on Korean pronunciation [4]. It is interesting for the present researchers to analyze on Korean pronunciation the original meaning of Chinese character, so the researchers took a role of trying to find the meaning of Chinese character.

\section{Materials and Methods}

The present researchers chose on random the Chinese characters, and counted them into the number of letters from 0051 to 0060 . From the parts of Chinese characters the researchers tried to find the appropriate meaning in Korean language.

\section{RESULTS AND DISCUSSION}

The researchers assembled a similar pronunciation from the separated parts of the Chinese characters, and wanted to find the meaning of the Chinese character on Korean words or sentences.

Copyright @ 2019: This is an open-access article distributed under the terms of the Creative Commons Attribution license which permits unrestricted use, distribution, and reproduction in any medium for non commercial use (NonCommercial, or CC-BY-NC) provided the original author and source are credited. 

character

Number, Pronunciation of the Chinese character (Chinese character): Meaning in Korean pronunciation of the Chinese

0051 Sig (植): "This seed is heavy (Mog[木] zig[直] $\rightarrow$ Mug zig), and this seed will be grown as a favorable plant!" (The original meaning)

'The plant' (the present meaning)

0052 Dong (動): "If it moves, I will kill (Zung[重] yeog[力] $\rightarrow$ Zug yeo) the animal!" (the original meaning).

'The animal' (the present meaning)

0053 Tchoi(最): "Why do you do that (Wal(日) i(耳) woo(又) $\rightarrow$ Wae ile yo)?" (the original meaning).

'The most and the best thing' (the present meaning)

0054 Myeong(明):

1) "Do your work completely (II[日] wol[月] $\rightarrow$ I lwo)!" (the original meaning).

"It is bright" (the present meaning).

2) "Let's break (Ddul[ I ] se[三]) the thought of the foolish person (Gon[ I ] bin[ח] i[二] $\rightarrow$ Gol bin i)!" (the original meaning).

"It is bright" (the present meaning).

$0055 \mathrm{Nae}$ (內)

1) 'It is this thing (I(入) gyeong[П] $\rightarrow$ I geot).' (The original meaning).

'The inner part' (the present meaning).

2) "The great man (woman)(Gon( I ) salam(人) $\rightarrow$ Keun salam) with the great work (Gon[ I ] il( $\rightarrow$ - $\rightarrow$ Keun il)!" (the original meaning).

'The inner part' (the present meaning).

0056 Gong (共):

1) "ls it true?" or "It is true (Zeong(井) pal(八) $\rightarrow$ Zeong mal)!" (the original meaning).

'Together' (the present meaning).

2) "We will do it with enthusiasm (Sin[ I ] i(二) ddul[ I ] yeo(八) $\rightarrow$ Sin i deul yeo)!" (the original meaning).

'Together' (the present meaning).

0057 Zo (兆):

1) "There are voices of talking (Zu[ $\backslash]$ byeol[/] zu[ $\backslash]$ byeol[/] in[人] $\rightarrow$ voices of talking)!" (The original meaning).

'The signal' (the present meaning).

2) "Show me (Byeol[/] zu[] sa[人] $\rightarrow$ Boyeo zu sa) a shining light (Bul[ $\backslash]$ bbitchim[/] $\rightarrow$ Bul bitchim), please!" (the original meaning). 'The signal' (the present meaning).

0058 Gyeol(結):

1) 'They became familiar each other, and they became connected as friends or as a wife and a husband (Sa[糸] gil[吉] $\rightarrow$ Sa gwil)' (the original meaning).

'They became connected' (the present meaning).

2) "We are going to connect 10 threads (Sil[ $[$ 糸 ] yeol[ $[+] \mathrm{il}[$ [ ] $\rightarrow$ Sil yeol eul) into a cord (Ib[口] $\rightarrow$ leo)" (the original meaning).

'To connect' (The present meaning).

0059 Gwi(貴):

1) 'The group of dancers (Tchung[虫] pae[貝] $\rightarrow$ Tchum pae)' (The original meaning).

'The precious thing or person' (The present meaning).

2) "This is a very joyful team (Ib[口] sin[ I ] hana[-] pae[貝] $\rightarrow$ I sin na pae), and they really enjoy their lives!" (The original meaning).

'The precious thing or person' (The present meaning). 


\section{$0060 \mathrm{~A}$ (我):}

1) "I who am not a special man (woman), but am an ordinary and simple man (woman) (Byeol[/] su[乎] gwa[戈] $\rightarrow$ Byeol su ga [lsseo]?)" (The original meaning).

'I, myself' (The present meaning).

2) "Oh wonderful! As the rice (Byeol[[] ga[戈] $\rightarrow$ Byeo ga) is going to be ripen (Byeol[l] il[ $[-]$ gwol[ []$\rightarrow$ Byeo ig eo). The head of rice is downward. Therefore, I want to change my characteristics in the good direction!" (The original meaning). 'I, myself' (The present meaning).

As a conclusion, through this research of Chinese characters, the researchers have found that the original meaning is more concrete than the presently used meaning.

\section{ACKNOWLEDGEMENTS}

We thank Mr Yeonghag Park and Mrs Hilye Sarah Kim, Mr Ilsoo Joseph Kim and Mrs Bohwa Kim, Ms Jieun Agatha Kim. We thank Father Jean Blanc and Father Hifumi Iwazaki. We thank Mrs Tamako Hayashi and Mr Yoshihiro Hayashi, Professor Byung Hoon Park and Professor Tae Song Koh and Professor In Sig Chang, the students of Department of Companion Animal and Animal Resources Science in Joongbu University and the members of Daejeon Ludovich of Ordo Franciscanus Saecularis(OFS).

\section{REFERENCES}

1. Fairbank, J. K., \& Reischauer, E. O. (1989). China: tradition \& transformation (Vol. 57). Boston: Houghton Mifflin Company.

2. Dallet, C. H. (1874). Histoire de l'Eglise de Corée (History of Korean Catholic Church). Victor Palme. Paris. France, 11-99.

3. Hyeonhi, R. P., Jieun, A. K., Kunjoo, D. A., Jiah, A. K., Sohwa, T. K., Kim, R., ... \& Sangdeog, A. K. (2017). Ancient Koreans petition to God in Tcheonzamun: The thousand character essay poem (641st to 656th letters). Journal of Languages and Culture, 8(6), 79-84.

4. Park, H.R., Kim, K.D.A., Kim, J.A., Kim, S.T., Kim, R., Hamon, A., Kim, S.A. (2019). The Story of Chinese Characters (0011-0020) When Translated On Korean Pronunciation. South Asian Res J Human Soc Sci, 1(3): 209-211. 